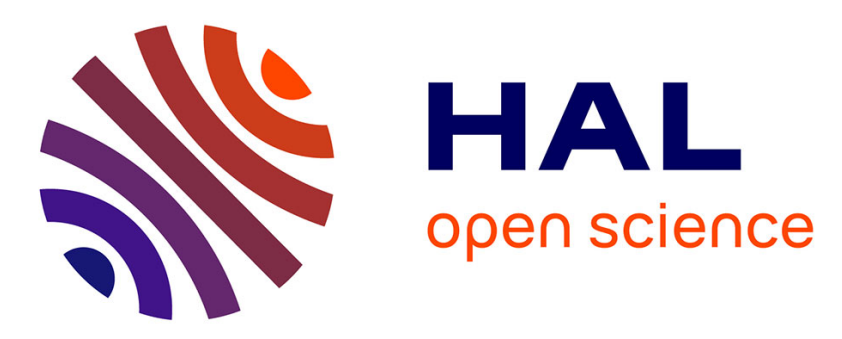

\title{
INTERSPECIFIC RELATIONSHIPS AMONG SOIL INVERTEBRATES INFLUENCE POLLUTANT EFFECTS OF PHENANTHRENE
}

\author{
Jérôme Cortet, Richard Joffre, Susanne Elmholt, Michael Coeurdassier, \\ Renaud Scheifler, Paul Henning Krogh
}

\section{To cite this version:}

Jérôme Cortet, Richard Joffre, Susanne Elmholt, Michael Coeurdassier, Renaud Scheifler, et al.. INTERSPECIFIC RELATIONSHIPS AMONG SOIL INVERTEBRATES INFLUENCE POLLUTANT EFFECTS OF PHENANTHRENE. Environmental Toxicology and Chemistry, 2006, 25 (1), pp.120. 10.1897/05-173R.1 . hal-03218735

\section{HAL Id: hal-03218735 \\ https://hal.science/hal-03218735}

Submitted on 5 May 2021

HAL is a multi-disciplinary open access archive for the deposit and dissemination of scientific research documents, whether they are published or not. The documents may come from teaching and research institutions in France or abroad, or from public or private research centers.
L'archive ouverte pluridisciplinaire HAL, est destinée au dépôt et à la diffusion de documents scientifiques de niveau recherche, publiés ou non, émanant des établissements d'enseignement et de recherche français ou étrangers, des laboratoires publics ou privés. 


\title{
INTERSPECIFIC RELATIONSHIPS AMONG SOIL INVERTEBRATES INFLUENCE POLLUTANT EFFECTS OF PHENANTHRENE
}

\author{
J'́ôme Cortet, R ichard Joffre,Susanne Elmholt, Michael Coeurdassier, Renaud Scheifler, \\ and Paul Henning Krogh \\ corresponding author: jerome.cortet@univ-montp3.fr
}

\begin{abstract}
Five mesofauna communities varying in both structure and composition were exposed to phenanthrene in mesocosms for up to four months. Effects of phenanthrene were assessed on mesofauna population dynamics, fungal biomass (ergosterol concentrations), and litter decomposition (litter mass loss, nitrogen concentration). The effects of each community on the fate of phenanthrene were also assessed. We hypothesize that phenanthrene affects the population dynamics of mesofauna and soil biological functioning depending on exposure duration, type of community, or both. Results show that phenanthrene exerted an effect on mesofauna and that the effects on some species, like Folsomia fimetaria, were influenced by the species composition in the mesocosms, the soil layer, and the sampling date. However, the effects of phenanthrene on ergosterol content and organic matter decomposition were not significantly influenced by community composition. These results demonstrate that interspecific relationships are needed to assess the toxicity of pollutants and should be taken into account in ecotoxicological risk assessment. Furthermore, this work does not support the hypothesis of a direct link between toxic effects of organic pollutants on mesofauna species and soil biological functioning.
\end{abstract}

Keywords-Organic pollutant compound Mesofauna communities Mesocosm Ergosterol Decomposition processes

\section{INTRODUCTION}

In recent years, various studies conducted on different ecosystems and organisms have shown the importance of species richness (number of species), functional richness (number of functions performed by the species), or both for the integrity of ecosystem processes [1-3]. For the soil ecosystem, it is usually suggested that the composition of species, functional groups (groups of species having the same function), or both might influence organic matter decomposition processes [4,5]. Concerning pollutant effects, Komulainen and Mikola [6] observed a clear reduction in respiration and nitrification in soils polluted by heavy metals because of a decrease in soil fauna. The respective role of soil mesofauna and macrofauna in the decomposition processes were, however, not clearly discriminated. Salminen et al. [7] demonstrated that the herbicide terbuthylazine modified the microarthropod community by affecting trophic interactions and thus indirectly disturbed the soil biological functioning.

Because of huge species variability of invertebrate sensitivity to pollutants, it is usually suggested that a battery of single-species bioassays performed on different organisms from different trophic levels would reduce uncertainty [8]. However, single-species tests continue to be used, neglecting interspecies relationships that can occur in natural soils. Thus, Kammenga and Laskowski [9] concluded that ignoring these interactions, as prey-predator relationships or competition, might hamper a proper risk assessment. Micro/mesocosm tools like terrestrial model ecosystems are useful tools to address species interactions in ecotoxicological risk assessment and to bridge the gap between single-species bioassays and the field [10].

In this work, we hypothesize that the effects of organic pollutants on mesofauna species dynamics depend on community structure and composition. Finally, these modifications could also have consequences for the effects of pollutants on decomposition processes.

To test these hypotheses, we conducted mesocosm experiments involving five mesofauna communities differing in species number and functional composition. The measured endpoints of population dynamics, fungal biomass, organic matter decomposition, and soil phenanthrene concentration were used in the model. Phenanthrene was used as the pollutant model because it is one of the most common polycyclic aromatic hydrocarbons (PAHs) and is considered a health risk in soil [11-13]. For instance, sewage sludge and sites polluted with oil and tar typically contain phenanthrene. Like most PAHs, phenanthrene is expected to accumulate in the environment. It is mainly found in the organic horizons of soils because of its resistance to decomposition processes and its high affinity for organic matter $\left(\log K_{\mathrm{ow}}=4.56\right)$ with low water solubility $(1,290 \mu \mathrm{g} / \mathrm{L})[14]$. 


\section{MATERIALS AND METHODS}

\section{Soil and litter}

Polyvinyl chloride cylinders $(10 \mathrm{~cm}$ high $\times 19 \mathrm{~cm}$ diameter $)$ were used as containers for the mesocosms. The soil was collected at Askov (Southern Jutland, Denmark), previously used as a representative of Northern European agricultural soils [11]. It is a sandy loam with the following texture: coarse sand (200-2,000 $\mu \mathrm{m}) 38.4 \%$, fine sand $(63-200 \mu \mathrm{m}) 23.6 \%$, coarse silt $(20-63 \mu \mathrm{m}) 10.0 \%$, fine silt $(2-20 \mu \mathrm{m}) 12.3 \%$, clay $(<2$ $\mu \mathrm{m}) 13.0 \%$. The soil $\mathrm{pH}\left(\mathrm{H}_{2} \mathrm{O}\right)$ was 6.2 . It was defaunated by alternately drying and freezing then sieving (2 mm mesh) [15]. Then, $2.6 \mathrm{~kg}$ (dry wt) of soil, corresponding to $1.2 \mathrm{~L}$, was transferred to each mesocosm and moistened to $15 \%$ (dry wt basis). Wheat straw litter (initial $\mathrm{C} / \mathrm{N}=168$ ), added as organic matter substrate, was cut into pieces of 5 to $10 \mathrm{~cm}$ length and dried at $60^{\circ} \mathrm{C}$ for $24 \mathrm{~h}$. A $1-\mathrm{mm}$ mesh nylon net was placed on the soil surface, and $4.0 \mathrm{~g}$ of litter was put on the net in each mesocosm and moistened with $15 \mathrm{ml}$ of deionized water.

Soil from half of the mesocosms was added to phenanthrene (purity $>96 \%$, Sigma-Aldrich, St. Louis, MO, USA), which had been dissolved in acetone (J.T. Baker, Hayward, CA, USA, high-performance liquid chromatography quality). The solution was mixed with the soil (proportion of 15\%), and acetone was evaporated under a fume head for $48 \mathrm{~h}$. The final nominal concentration of phenanthrene in contaminated containers was $43 \mathrm{mg} / \mathrm{kg}$ soil, which corresponds to the $50 \%$ lethal concentration (LC50) for Folsomia fimetaria with the same soil [12]. This is a high level of phenanthrene soil contamination, although higher concentrations have been reported in industrially contaminated soils [16]. Wheat straw litter for these mesocosms was also contaminated before being added to the polluted mesocosms. This was done by soaking each sample to the phenanthrene-acetone solution for $1 \mathrm{~min}$ and evaporating the acetone under a fume head for $24 \mathrm{~h}$.

All containers were inoculated with a soil extract to stimulate microbial activity in the mesocosms. The soil extract was prepared by mixing and gently shaking $100 \mathrm{~g}$ of fresh Askov soil with $1 \mathrm{~L}$ of deionized water. After one night decanting, $0.5 \mathrm{~L}$ of the supernatant was filtered through a $10-\mu \mathrm{m}$ mesh [17]. The filtrate was diluted to $1 \mathrm{~L}$, and $30 \mathrm{ml}$ of this solution was sprayed on the wheat straw litter of each mesocosm. The mesocosms were weighed and transferred to a dark $20^{\circ} \mathrm{C}$ room for $48 \mathrm{~h}$ before animal addition.

\section{Community compositions}

Five different communities were constructed, including three trophic levels. Microflora-microfauna (MIC), including fungi, bacteria, protozoa, and nematodes, without mesofauna, assesses decomposition effects of microbial activity without interference from grazing or predation by the soil mesofauna. Three treatments included microflora-microfauna and detritivorous mesofauna: F. fimetaria (FF), which adds one collembolan species to MIC; Collembola (COL), which adds four other collembolan species having different ecological nichesIsotomurus prasinus, Hypogastrura assimilis, Mesaphorura macrochaeta, and Protaphorura armata - to FF; and detritivorous (DET), which adds an enchytraeid species, Enchytraeus crypticus, to COL. Most of these mesofauna species are usually considered to be fungal feeders, although omnivory cannot be excluded. The last treatment included a predatory species (PRED), which adds the predaceous mite Hypoaspis aculeifer to DET.
The species were chosen as representative of various ecological niches: $F$. fimetaria is known as a euedaphic, nonpigmented, eyeless species that reproduces sexually. Hypogastrura assimilis also reproduces sexually, but differs from the aforementioned species by being epi- to hemiedaphic and pigmented, as well as having eyes made of eight ommatidia [18]. Isotomurus prasinus is a typical epiedaphic species that reproduces sexually. It is well adapted to surface litter life, with eyes, hair, and a strong mobility. Mesaphorura macrochaeta and $P$. armata are typically parthenogenetic euedaphic species. Enchytraeus crypticus is a euedaphic enchytraeid [19]. Hypoaspis aculeifer has an arrhenotokous mode of reproduction [20] (i.e., only male offspring are produced from unfertilized females). This species is characterized as being polyphagous and having a hemiedaphic/euedaphic distribution [21].

Folsomia fimetaria, M. macrochaeta, P. armata, $H$. assimilis, E. crypticus, and $H$. aculeifer were obtained from laboratory cultures. Isotomurus prasinus was collected from a noncontaminated field by extraction of litter samples under light and transferred to petri dishes. Twenty individuals of each species F. fimetaria, M. macrochaeta, I. prasinus, and $H$. assimilis; 10 individuals of P. armata; and 40 individuals of E. crypticus were added to the corresponding mesocosms according to treatment. Twenty sexually mature H. aculeifer (10 males and 10 females) were added to PRED mesocosms $48 \mathrm{~h}$ after addition of the detritivores. This number and proportion of individuals was estimated to be the minimum needed to obtain a viable and reproductive population for each species in the mesocosms. After animal addition, mesocosms were weighed and moisture was weekly adjusted by spraying ionized water onto the litter to maintain approximately $15 \%$ soil water content (water holding capacity). A transparent plastic film with holes for aeration covered each mesocosm. Containers were stored at $15^{\circ} \mathrm{C}$ with $12 \mathrm{~h}$ of periodic light before sampling.

\section{Mesofauna extraction and evaluation}

At both sampling dates (30 and $120 \mathrm{~d}$ ), microarthropods were extracted from the litter under $60 \mathrm{~W}$ light for $2 \mathrm{~d}$ into a benzoic acid solution. After extraction, the wheat litter was stored at $-18^{\circ} \mathrm{C}$. Furthermore, because of the introduction of both epigeic and endogeic species, mesofauna was extracted from the top ( 0 to $-1 \mathrm{~cm}$ of upper soil) and the remaining bottom soil ( -1 to $-4 \mathrm{~cm})$. After separation of the two layers, the soil was gently homogenized, and a weighed subsample (200 $\mathrm{g}$ of fresh soil) was taken from each layer. Microarthropods were extracted from the soil with a high-gradient extractor (Macfadyen type) [22]. After extraction from soil and litter, animals were preserved in glycerol and counted under a binocular microscope. The lengths of 100 randomly selected representatives of each species from each layer and each sampling date were measured under the microscope. Then, lengths were transformed into biomass with equations derived from laboratory measurements on the same species or equivalent species, as described by Petersen [23]. Predatory mite biomass was estimated by using data from literature [24].

Enchytraeids were extracted from the two soil layers by immersion in water of a 70-g fresh soil subsample [25]. The animals were counted under a binocular microscope. The biomass was estimated from data in the literature [24]. The enchytraeids were not extracted from the litter layer; indeed, the separation of the litter into two subsamples, one for microar- 
thropod extraction and one for enchytraeid extraction, could have greatly disturbed microarthropod extraction efficiency.

\section{Spectral analysis of litter samples and near-infrared reflectance spectrophotometer calibration}

This procedure has been described by Cortet et al. [5] Briefly, remaining litter from the samples was dried $(24 \mathrm{~h}$, $45^{\circ} \mathrm{C}$ ) and milled with a Cyclotec 1093 (1-mm mesh size; Tecator, Höganäs, Sweden). All samples were scanned with a near-infrared reflectance spectrophotometer (NIRS system 6500, Foss Nirs systems, Silver Spring, MD, USA). Representative samples were analyzed for ash residues, nitrogen $(\mathrm{N})$ content, and ergosterol as described in Cortet et al. [5], the latter used as an indicator of fungal biomass. Calibrations were then developed to predict ash residue and nitrogen and ergosterol concentrations for all samples with the use of measured reference data and spectra obtained from the NIRS. The ash-free litter mass remaining (LMR) was calculated for each sample with Equation 1.

$$
\mathrm{LMR}_{i}=100 \cdot \frac{\mathrm{MD}_{i}}{\mathrm{MD}_{0}} \cdot \frac{100-\mathrm{AT}_{i}}{100-\mathrm{AT}_{0}}
$$

$\mathrm{LMR}_{i}$ is the percent remaining litter mass of sample $i, \mathrm{MD}_{i}$ is the final (i.e., after sampling) dry mass of sample $i, \mathrm{MD}_{0}$ is the initial dry mass of sample $i, \mathrm{AT}_{i}$ is the percent total ash concentration of sample $i$, and $\mathrm{AT}_{0}$ is the initial percent total ash concentration of sample $i$. From the estimated $\mathrm{N}$ and ash content of each sample, $\mathrm{N}$ concentration in organic matter can be calculated for each sample (Eqn. 2).

$$
T_{i}=100 \cdot \frac{\mathrm{NC}_{i}}{100-\mathrm{AT}_{i}}
$$

$T_{i}$ is percent $\mathrm{N}$ concentration in organic matter for sample $i$ and $\mathrm{NC}_{i}$ is the $\mathrm{N}$ concentration in sample $i$.

\section{Soil phenanthrene analysis}

Soil samples from the different treatments were collected at $t=120 \mathrm{~d}$, corresponding to a long-term exposure to the pollutant. Phenanthrene was analyzed by two different methods. However, statistical analyses showed that results were not significantly influenced by the methodology. Eight samples were analyzed as described by Hestbjerg et al. [26], with microwave extraction in acetone:dichloromethane:water (1:1: $0.17)$ and deuterated phenanthrene $\left(\right.$ PHE- $\left.\mathrm{D}_{10}\right)$, followed by gas chromatography mass spectrometry analysis. Twenty-two other samples were analyzed by an accredited laboratory (AnalyCen, Fredericia, Denmark) by extraction with $20 \mathrm{ml}$ of $0.05 \mathrm{M}$ sodium pyrophosphate and $20 \mathrm{ml}$ of toluene with an internal standard (deuterated fluoranthene, phenanthrene, and benz $[a]$ pyrene). The extraction was continued for $16 \mathrm{~h}$. The extracts were analyzed by gas chromatography mass spectrometry. Three replicates from each community composition (MIC, FF, COL, DET, PRED) and each layer (top soil and bottom soil) were analyzed.

\section{Statistics}

The mesocosms were sorted into six series, corresponding to the six replicates (called here blocks) and comprising all community compositions. In total, 120 mesocosms were initiated corresponding to five community compositions, one level of phenanthrene and control, two sampling dates (30 and $120 \mathrm{~d}$ after exposure), and six blocks. The total duration of the experiment was 4 months. At each sampling date and for each treatment, six mesocosms were randomly collected and sacrificed for analysis.

Linear mixed effects models were produced to predict species biomass (log transformed), LMR, ergosterol concentration, $\mathrm{N}$ concentration, and soil phenanthrene concentration at each sampling date, assuming phenanthrene effect, community composition (MIC, FF, COL, DET, and PRED), and layers (litter, top soil, and bottom soil) as fixed factors and blocks as a random factor. A possible correlation between layers was tested by including a correlation factor in the models. The best models (with or without correlation between layers) were chosen for each predicted parameter, looking at the Akaike index. Significant effects of fixed factors and their interactions were then evaluated by analysis of variance [27]. All means were compared by Fisher's tests. All statistical treatments were performed by R 1.8.1. software [28].

\section{RESULTS}

\section{Effects of phenanthrene on mesofauna}

The effects of phenanthrene on biomass varied according to animal species. After $30 \mathrm{~d}$, a strong negative effect was observed on F. fimetaria $(p<0.0001), I$. prasinus $(p<$ $0.0001), P$. armata ( $p=0.02)$, and E. crypticus $(p=0.04)$ (Fig. 1). After $120 \mathrm{~d}$, a decrease in biomass was still observed in F. fimetaria $(p<0.001)$ and appeared in $M$. macrochaeta $(p=0.001)$, whereas a significant increase was observed in I. prasinus ( $p=0.0002)$. No significant effects were observed in $H$. assimilis and $H$. aculeifer. However, in some cases, mesocosm communities significantly influenced the effects of phenanthrene. Indeed, after $120 \mathrm{~d}$, phenanthrene induced a significant decrease in F. fimetaria in the plurispecies mesocosms, COL, DET, and PRED and an increase in I. prasinus in PRED only (Fig. 1).

For some species, the effects of phenanthrene varied depending on the soil layer (Fig. 2). For instance, the biomass of M. macrochaeta was significantly reduced by phenanthrene after $120 \mathrm{~d}$, but only in the top soil. After $120 \mathrm{~d}, \mathrm{~F}$. fimetaria also responded differently to phenanthrene depending on the soil layer ( $p=0.0052$ ), a decrease of biomass being measured only in the litter layer. For the predator $H$. aculeifer after 30 $\mathrm{d}$, a greater biomass was found in the top soil compared with litter and in the litter compared with bottom soil (Fig. $2 ; p<$ 0.001). A significant interaction between phenanthrene and layer was also noticed in $H$. aculeifer after $120 \mathrm{~d}(p=0.008)$, with only a significant decrease in the topsoil.

\section{Effects of phenanthrene on ergosterol concentration and wheat straw decomposition processes ( $N$ concentration and litter mass remaining)}

For LMR after $30 \mathrm{~d}$, we found no difference between phenanthrene and control treatments or between community compositions (Fig. 3). After 120 d, however, a significant negative effect was observed with phenanthrene, indicating greater decomposition when the pollutant was present $(p<0.001)$. No interaction occurred between phenanthrene and community composition, even though a greater decomposition was observed in MIC compared with DET (Fig. 3). After both 30 and $120 \mathrm{~d}$, litter ergosterol concentrations were significantly greater in phenanthrene-treated mesocosms than controls ( $p$ $<0.001$; Fig. 3). After 30 d, no difference was observed between community compositions and no interaction occurred between phenanthrene and community composition. After 120 

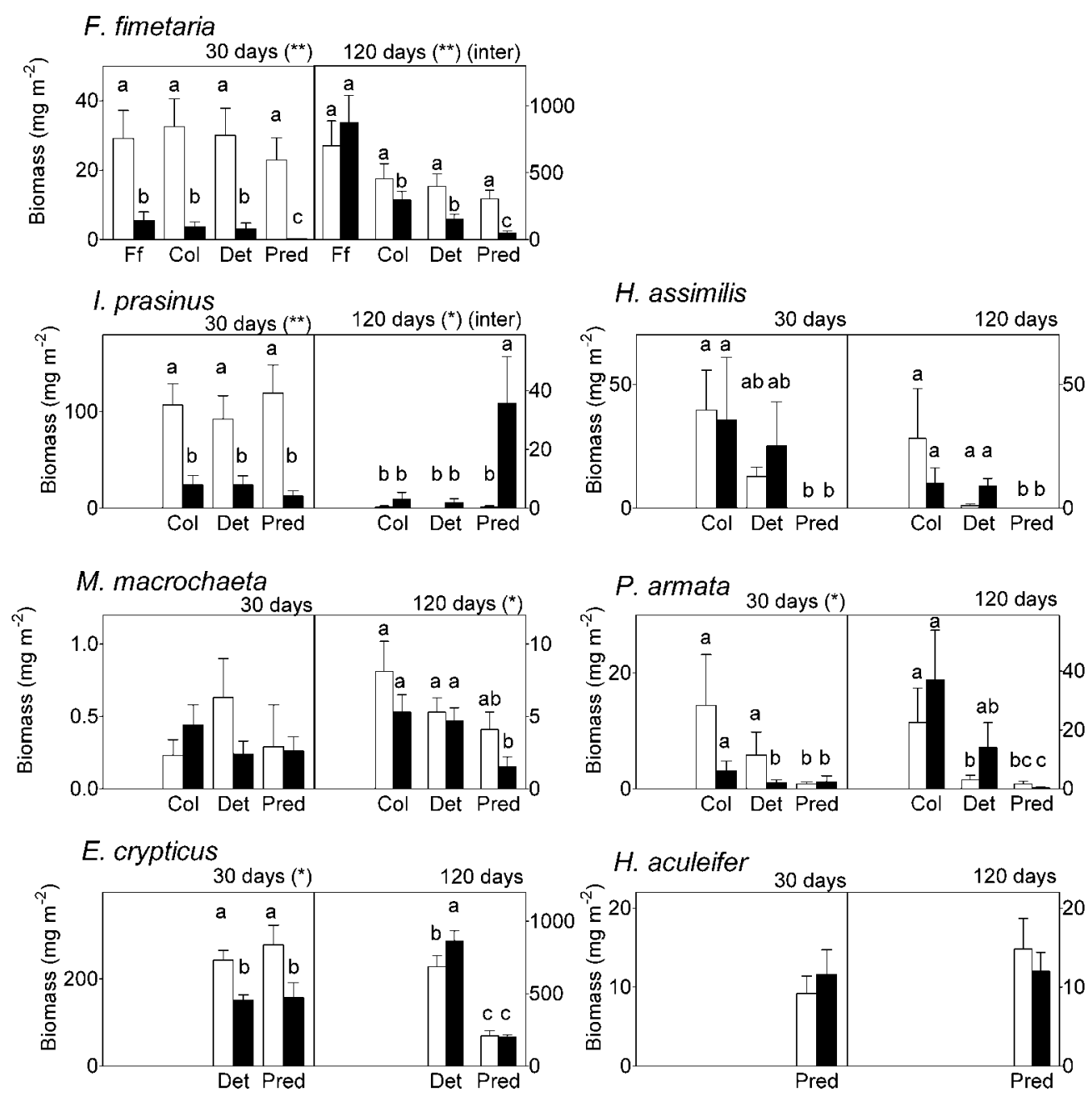

Fig. 1. Biomass (means and standard errors) of each taxon present in the mesocosms at $t=30$ and $120 \mathrm{~d}$ for each community compositionFolsomia fimetaria (FF), collembola (COL), detritivorous (DET), predator (PRED) — and each treatment (control with white bars, phenanthrene with black bars), all layers considered altogether. Significant effects of phenanthrene at each sampling date are $* p<0.05$ or $* * p<0.01$. Inter $=$ interactions between community compositions and phenanthrene treatment. Different letters above each bar indicate significant differences. Analysis of variance was conducted on 144 samples for the species Folsomia fimetaria (four community compositions, FF, COL, DET, and PRED; two treatments, C and P; three vertical layers; six time-block series), 108 samples for the species Hypogastrura assimilis, Isotomurus prasinus, Mesaphorura macrochaeta, Protaphorura armata (three community compositions, COL, DET, and PRED; two treatments, C and P; three vertical layers; six time-block series), 48 samples for Enchytraeus crypticus (two community compositions, DET and PRED; two treatments, $\mathrm{C}$ and P; two soil layers; six time-block series), 36 samples for Hypoaspis aculeifer (two treatments, C and P; three vertical layers; six timeblock series). Fisher's tests $(p<0.05)$ were used for a posteriori tests.

d, ergosterol concentration was significantly greater in MIC compared with DET and PRED. However, no interaction occurred between phenanthrene and community composition at this sampling date. Litter $\mathrm{N}$ concentrations after $30 \mathrm{~d}$ were not affected by phenanthrene, nor were their interactions between community composition and phenanthrene (Fig. 3). After 120 $\mathrm{d}, \mathrm{N}$ concentrations were greater in MIC compared with COL and DET. Nitrogen concentrations were also greater in phenanthrene-treated mesocosms compared with controls $(p<$ 0.001 ), but no interaction between phenanthrene and community composition occurred.

\section{Fate of phenanthrene in the soil}

Phenanthrene concentrations decreased in the soil from the start: $t=0 \mathrm{~d}$ (nominal concentration $43 \mathrm{mg} / \mathrm{kg}$ ) to $t=120 \mathrm{~d}$ (Fig. 4). In the bottom soil, contrary to the top soil, the degradation was significantly greater when community composition increased ( $p<0.001$; Fig. 4). Furthermore, phenan- threne disappearance was greater in the top soil compared with the bottom soil $(p=0.003)$.

\section{DISCUSSION}

\section{Effects on mesofauna}

Our results demonstrate that specific responses to pollutants are strongly mediated by the soil fauna community type through predation and competition effects, modifying significantly the conclusion that would be reached in risk assessment on the basis of single-species tests. Indeed, in the most complex mesocosm PRED, F. fimetaria was stressed by three factors: phenanthrene, predation by $H$. aculeifer, and competition with other collembolan species. In this context, the energy allocated by $F$. fimetaria to predation avoidance and competition in PRED could have increased its sensitivity to phenanthrene compared with the other community compositions. Predictive models on nematode communities have also re- 

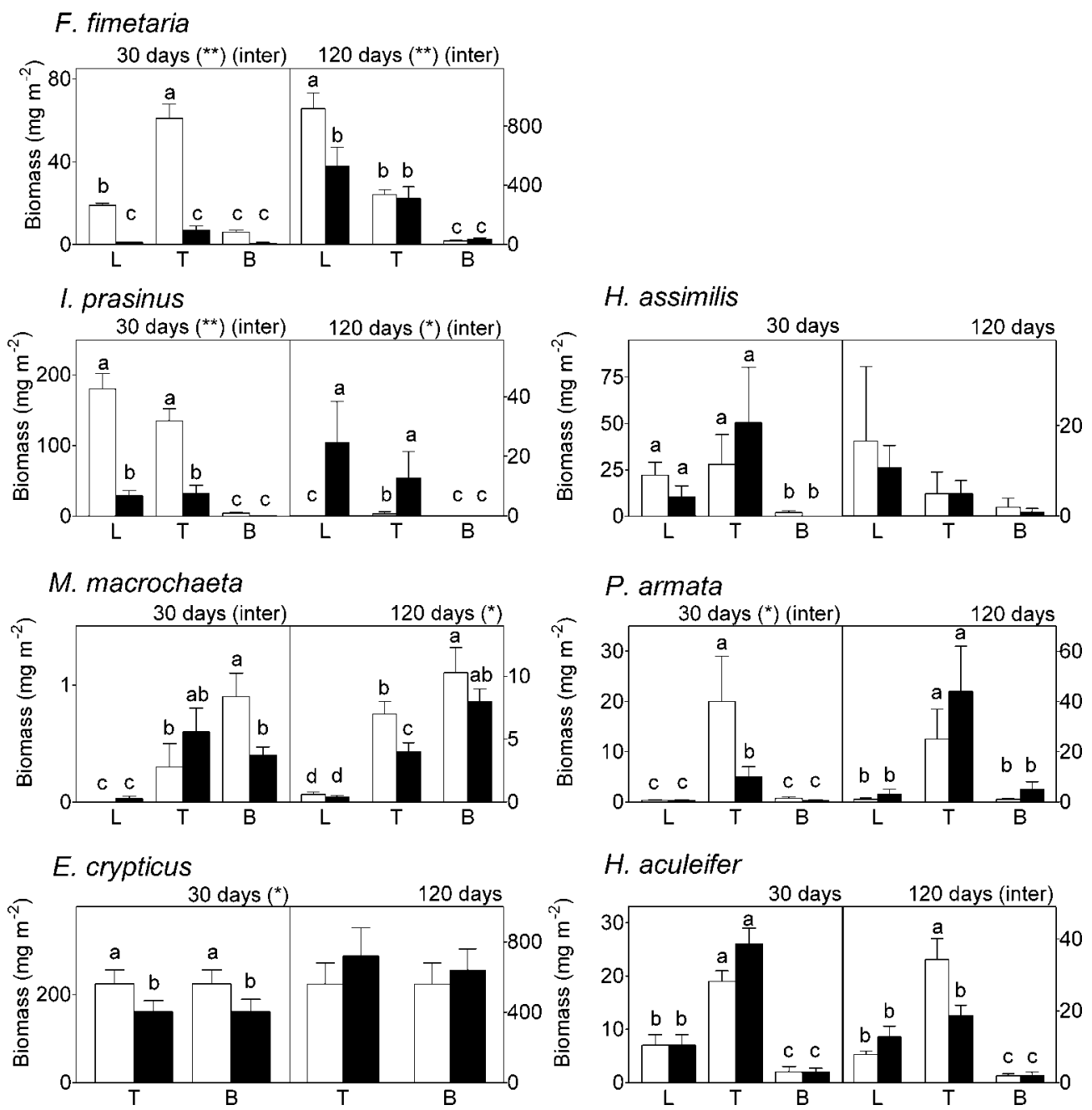

H. aculeifer

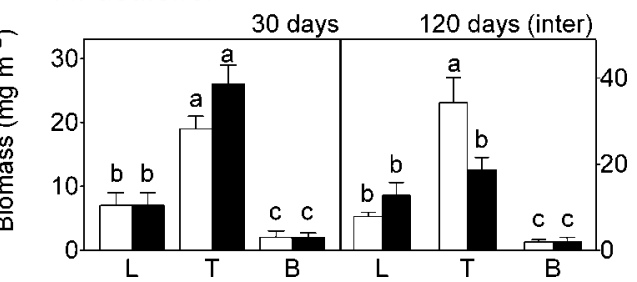

Fig. 2. Biomass (means and standard errors) of each taxon present in the mesocosms at $t=30$ and $120 \mathrm{~d}$ for each vertical layer (litter, top soil, and bottom soil) and each treatment (control with white bars, phenanthrene with black bars), the community compositions considered together. Significant effects of phenanthrene at each sampling date are $* p<0.05$ or $* * p<0.01$. Inter $=$ interactions between layers and phenanthrene treatments. Different letters above each bar indicate significant differences (analysis of variance; see Fig. 1 for more information).

ported that competition could greatly increase the sensitivity of the populations to toxic stress [29].

A layer-dependent phenanthrene effect was also observed. For F. fimetaria, it was probably caused by increased competition from other species in the litter layer compared with the soil layers. After $120 \mathrm{~d}$, for instance, the litter-dwelling $I$. prasinus showed greater biomass with phenanthrene compared with the control, and it might well have outnumbered $F$. $f$ metaria. For $H$. aculeifer, the biomass differences between layers are not surprising because it was confirmed to have an aggregative prey search pattern and to stay where food is available $[30,31]$ in the upper layers. However, the interaction between phenanthrene and layers after $120 \mathrm{~d}$ is more difficult to explain for this predator because the total number of prey animals did not decrease significantly with phenanthrene in the top soil. However, some simulation models of two-species ecotoxicological test systems involving $F$. fimetaria and $H$. aculeifer demonstrated that a decrease in capture efficiency by the predator negatively affected its reproduction [31].

These results also confirm that responses to phenanthrene toxicity are highly dependent on the species and highlight the need to take into account this dependence of response in ecotoxicological risk assessments (ERAs). For instance, and in accordance with previous studies [12], F. fimetaria shows higher sensitivity to phenanthrene than E. crypticus. For the predator $H$. aculeifer, the absence of significant phenanthrene effects, at least after $30 \mathrm{~d}$, could be explained by the diversity of available prey, some of which are not at all or are less affected by phenanthrene, such as $H$. assimilis or E. crypticus. Furthermore, this mite species could be less sensitive to pollutants than its available prey, as shown with dimethoate in a two-species toxicity test system [32].

\section{Effects on decomposition processes}

In this study, we demonstrate that phenanthrene and community composition influenced decomposition processes, but according to our statistical analysis, they act independently, in contrast to the interaction between phenanthrene and community composition identified for $F$. fimetaria. Consequently, the decrease in grazers observed in phenanthrene-treated mesocosms is not responsible for the fungal increase (measured here via ergosterol content). The fungal increase in litter was equivalent for all mesocosms irrespective of community treatment. This increase could result for more than one reason. First, the phenanthrene was dissolved in acetone, and the litter was soaked in this liquid for $1 \mathrm{~min}$, whereupon the acetone 

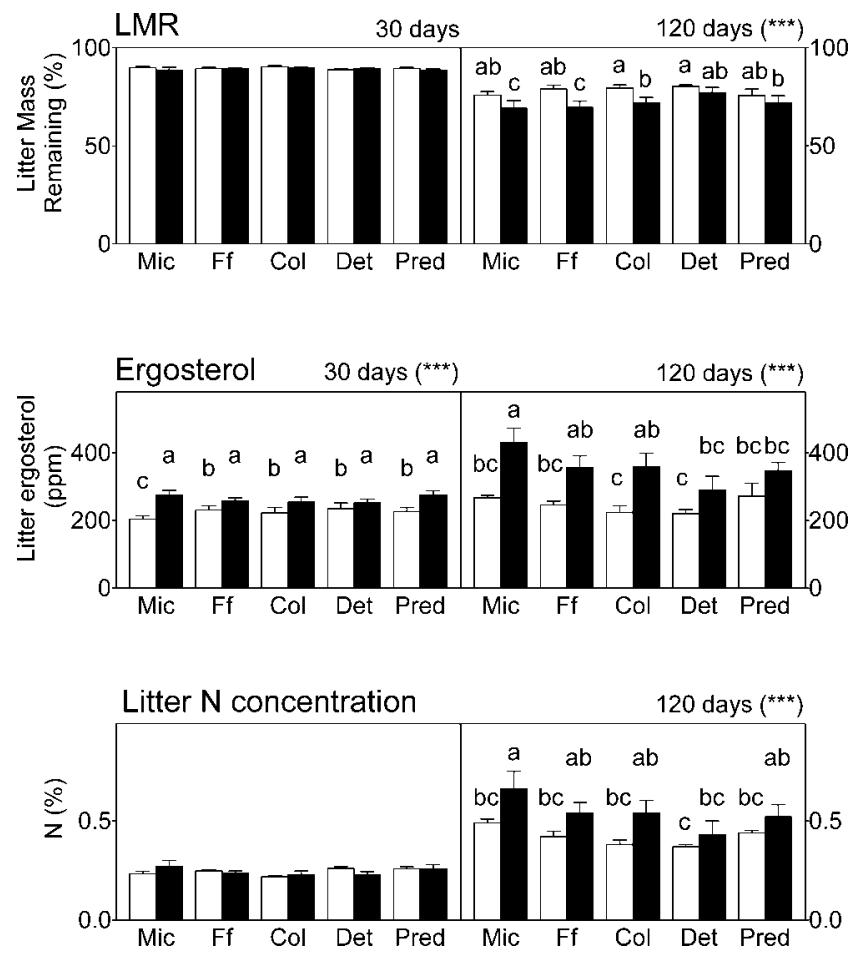

Fig. 3. Litter mass remaining (LMR), ergosterol, and nitrogen in the litter at each sampling date $(t=30$ or $120 \mathrm{~d})$ and for each type of treatment (means and standard deviations). Significant differences between treatments (control with white bars, phenanthrene with black bars) are $* * * p<0.05$ (analysis of variance, 60 samples, Fisher's tests). Significant differences between treatments within post hoc tests are expressed by different letters at each sampling occasion. For explanation of treatments, see text; see Fig. 1 legend for definition of abbreviations.

was allowed to evaporate for $24 \mathrm{~h}$. This leaves time for the acetone to affect the litter and might have rendered it more susceptible to fungal invasion. Acetone has, for example, been shown to affect enzyme activities, probably by an effect on soil organic matter [33]. Second, phenanthrene itself could have caused an increase in ergosterol because the compound might act as a source of carbon or energy for fungi [34]. With the present design, however, effects of acetone and phenan-

\section{Phenanthrene}

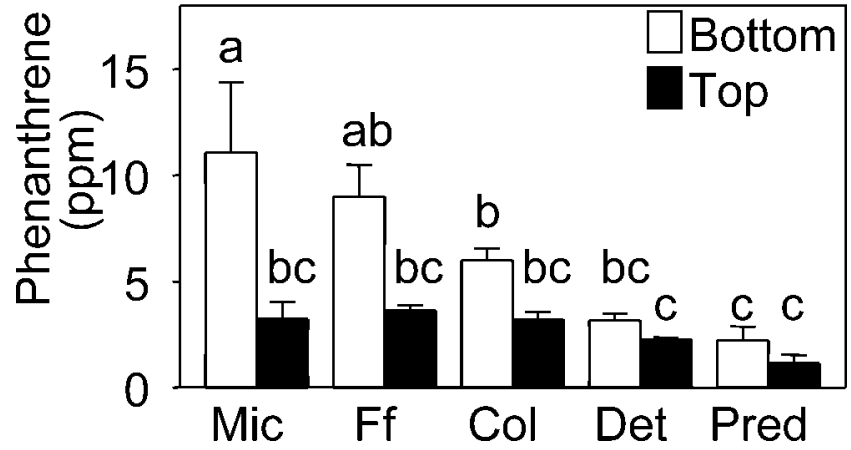

Fig. 4. Phenanthrene concentrations (means and standard deviations) in the top soil and the bottom soil after $120 \mathrm{~d}$ for each community composition. Different letters on bars indicate differences (analysis of variance on 30 samples [five community compositions, two vertical layers, three replicates]; Fisher's tests $(p<0.05)$ were used for a posteriori tests). MIC = microflora-microfauna; see Fig. 1 legend for definition of other abbreviations. threne cannot be separated and must be evaluated in total. No matter the reason, the increase in ergosterol as an indicator of fungal biomass seems to have stimulated decomposition processes because litter nitrogen concentration and litter decomposition were significantly increased with phenanthrene.

\section{Fate of phenanthrene}

Our results confirm that soil fauna can contribute to the remediation of soils contaminated by phenanthrene [35]. They also show that the different community compositions responded differently to phenanthrene addition, strongly suggesting that soil mesofauna composition should be taken into account when studying the fate of organic pollutants in soil. In our case, increasing soil mesofauna composition has probably increased the functional dissimilarity in soil that can have enhanced mesofauna activity (such as soil foraging and mixing) or changed soil microflora composition, which could have finally contributed to reduce phenanthrene in the soil. However, further studies are needed to elucidate whether the observed increase in phenanthrene degradation following an increase in soil biodiversity is actually due to the increase in biodiversity or degrader biomass or, most likely, a combination of both. Furthermore, some recent studies concluded that soil communities with the same species number, but differing by species composition, might have very different effects on soil ecosystem processes, suggesting that increasing functional dissimilarity does not always result in facilitation of soil functioning [36].

Differences in phenanthrene degradation between the top and bottom soils might be ascribed to the top soil having higher oxygen availability or lower volatile content, with a potentially negative effect on biological activity compared with the bottom soil [16]. Greater photodegradation on the surface compared with the bottom soil is also possible. Furthermore, our mesocosms were inoculated with a soil extract, which was applied on the straw on top of the soil; consequently, the decomposition of phenanthrene in the top soil could have been stimulated more than in the bottom soil. Moreover, the total mesofauna biomass was greater in the top soil than in the bottom soil, irrespective of the biodiversity treatment. This might directly or indirectly have affected phenanthrene concentrations by soil animals consuming and disseminating more phenanthrene-degrading microorganisms in the top soil [37].

\section{Consequences for ERA}

Our results illustrate how risk assessment conclusions can differ completely when a species is tested alone or when it interacts with other species. Indirect effects of pollutants via competition or predation interactions among species are probably crucial in most natural ecosystems. Although community structure is a complex factor to describe, it should be taken into account like other modifying factors such as $\mathrm{pH}$, temperature, soil type, and exposure. Therefore, we propose to include a multispecies test in standard procedures for the assessment of pollutant effects. The major question is to choose the appropriate community for the mesocosms to obtain the highest degree of generalization. We have composed our community with representatives of the main life forms and trophic levels, including epiedaphic, hemiedaphic, and euedaphic collembolan species, as well as a worm and a mite predator. For practical reasons, we have used species that were easy to collect or keep in permanent laboratory cultures, and it can be questioned whether these constructed communities are too ar- 
tificial and too far from field communities, thus facing some of the same problems as single-species tests. Thus, the level of representation of these mesocosms and connections with current single-species tests, for which there exist standard protocols for three of the species used ( $F$. fimetaria [38], $H$. aculeifer [39], and E. crypticus [40]), need further investigation. Furthermore, to be validated, a range of concentrations of different kinds of pollutants must be tested, as well as the replicability of the responses of the species in these mesocosms for several endpoints that need also to be selected (e.g., no observed effect concentration and lethal or sublethal concentration). On the other hand, the use of multispecies communities would severely increase costs unless single-species tests were substituted. It thus seems reasonable to use the same community for all the tests, with species that are frequently used in bioassays and whose life cycles are quite well known.

Furthermore, even if a function is controlled by species richness or any parameter belonging to the structure of communities, a disturbance can independently modify both the structure of communities and the function. Thus, when looking at pollutant effects on the environment, it is necessary to analyze effects both on communities and functions and to avoid hypothetical predictions on functional parameters from observed effects on communities.

\section{CONCLUSION}

The toxicity of phenanthrene to mesofauna species in mesocosms was influenced by several factors, including species sensitivity to the pollutant, the initial community introduced into the mesocosm, and the sampling layer. Furthermore, the phenanthrene fate varied according to the mesofauna community introduced into the mesocosm, with higher degradation rates in the most complex communities. On the other hand, no interaction was observed between phenanthrene and community effects on decomposition processes. It is thus concluded that interspecific relations should be taken into account and that community and functional endpoints should both be assessed at the same time in ERA strategies.

Acknowledgement-This work was supported by the European Science Foundation Program on Linking Community and Ecosystem Ecology (LinkEcol), the Center for Biological Processes in Contaminated Soils and Sediments (BIOPRO), and the European Unionfounded program Soil Ecological and Economic Evaluation of Genetically Modified Crops (ECOGEN). Thanks to David Pleydell (University of Salford, UK), Steven Criquet (Institut Méditerranéen d'Ecologie et Paléoécologie, Marseille, France), Philippe Binet (Université de Franche Comté), Kees van Gestel (Free University, Amsterdam, The Netherlands), and two anonymous referees for improving the manuscript. We also thank Zdenek Gavor, Karen Kjær Jacobsen, Elin Jørgensen, Trine G. Sørensen, Anni Christiansen, Egon Frandsen, and Jørgen M. Nielsen, as well as Lene Birks $\emptyset$ (National Environmental Research Institute, Denmark).

\section{REFERENCES}

1. Tilman D, Knops J, Wedin D, Reich P, Ritchie M, Siemann E. 1997. The influence of functional diversity and composition on ecosystem processes. Science 277:1300-1302.

2. Loreau M, Naeem S, Inchausti P, Bengtsson J, Grime JP, Hector A, Hooper DU, Huston MA, Raffaelli D, Schmid B, Tilman D, Wardle DA. 2001. Biodiversity and ecosystem functioning: Current knowledge and future challenges. Science 294:804-808.

3. Mebes K, Filser J. 1998. Does the species composition of Collembola affect nitrogen turnover? Appl Soil Ecol 9:241-247.

4. Cragg RG, Bardgett RD. 2001. How changes in soil faunal diversity and composition within a trophic group influence decomposition processes. Soil Biol Biochem 33:2073-2081.

5. Cortet J, Joffre R, Elmholt S, Krogh PH. 2003. Increasing species and trophic diversity of mesofauna affects fungal biomass, mesofauna community structure and organic matter decomposition processes. Biol Fertil Soils 37:302-312.

6. Komulainen M, Mikola J. 1995. Soil processes as influenced by heavy metals and the composition of soil fauna. J Appl Ecol 32: 234-241.

7. Salminen J, Setälä H, Haimi J. 1997. Regulation of decomposer community structure and decomposition in herbicide stressed humus soil. Appl Soil Ecol 6:265-274.

8. Bierkens J, Klein G, Corbisier P, Van den Heuvel R, Verschaeve L, Weltens R, Schoeters G. 1998. Comparative sensitivity of 20 bioassays for soil quality. Chemosphere 37:2935-2947.

9. Kammenga J, Laskowski R. 2000. Demographic approaches in ecotoxicology-Open problems. In Kammenga J, Laskowski R, eds, Demography in Ecotoxicology. John Wiley, Chichester, UK, pp 265-275.

10. Van Gestel CAM, Weeks JM. 2004. Recommendations of the 3rd International Workshop on earthworm ecotoxicology, Aarhus, Denmark, August 2001. Ecotoxicol Environ Saf 57:100-105.

11. Sverdrup LE, Ekelund F, Krogh PH, Nielsen T, Johnsen K. 2002. Soil microbial toxicity of eight polycyclic aromatic compounds: Effects on nitrification, the genetic diversity of bacteria and the total number of protozoans. Environ Toxicol Chem 21:16441650.

12. Sverdrup LE, Kelley AE, Krogh PH, Nielsen T, Jensen J, ScottFordsmand JJ, Stenersen J. 2001. Effects of eight polycyclic aromatic compounds on the survival and reproduction of the springtail Folsomia fimetaria L. (Collembola, Isotomidae). Environ Toxicol Chem 20:1332-1338.

13. Sverdrup LE, Jensen J, Kelley AE, Krogh PH, Stnersen J. 2002. Effects of eight polycyclic aromatic compounds on the survival and reproduction of Enchytraeus crypticus (Oligochaeta, Clitellata). Environ Toxicol Chem 21:109-114.

14. Mackay D, Shiu WY, Ma KC. 1992. Illustrated Handbook of Physical-Chemical Properties and Environmental Fate for Organic Chemicals. Polynuclear Aromatic Hydrocarbons, Polychlorinated Dioxins and Dibenzofurans. Lewis, Boca Raton, FL, USA.

15. Krogh PH. 1995. Effects of pesticides on the reproduction of Hypoaspis aculeifer (Gamasida: Laelapidae) in the laboratory. Acta Zool Fenn 196:333-337.

16. Joner EJ, Hirmann D, Szolar OHJ, Todorovic D, Leyval C, Loibner AP. 2004. Priming effects on PAH degradation and ecotoxicity during a phytoremediation experiment. Environ Pollut 128:429435.

17. Huhta V, Wright DH, Coleman DC. 1989. Characteristics of defaunated soil I. A comparison of three techniques applied to two different forest soils. Pedobiologia 33:417-426.

18. Folker-Hansen P, Krogh PH, Holmstrup M. 1996. Effect of dimethoate on body growth of representatives of the soil living mesofauna. Ecotoxicol Environ Saf 33:207-216.

19. Martikainen E. 1996. Toxicity of dimethoate to some soil animal species in different soil types. Ecotoxicol Environ Saf 33:128136.

20. De Jong JH, Lobbes PV, Bolland HR. 1981. Karyotypes and sex determination on two species of laelapid mites (Acari: Gamasida). Genetica 55:187-190.

21. Sardar MA, Murphy PW. 1987. Feeding tests of grassland soil inhabiting gamasina predators. Acarologia 28:117-121.

22. Petersen H. 1978. Some properties of two high-gradient extractors for soil micro-arthropods, and an attempt to evaluate their extraction efficiency. Nat Jutl 20:95-121.

23. Petersen H. 1975. Estimation of dry weight, fresh weight, and calorific content of various collembolan species. Pedobiologia 15:222-243.

24. Petersen H, Luxton M. 1982. A comparative analysis of soil fauna populations and their role in decomposition processes. Oikos 39: $288-388$.

25. O'Connor FB. 1955. Extraction of enchytraeid worms from a coniferous forest soil. Nature 175:815-816.

26. Hestbjerg H, Willumsen PA, Christensen M, Andersen O, Jacobsen CS. 2003. Bioaugmentation of tar-contaminated soils under field conditions using Pleurotus ostreatus refuse from commercial mushroom production. Environ Toxicol Chem 22:692-698.

27. Pinheiro JC, Bates DM. 2000. Mixed-Effects Models in S and SPLUS. Springer Verlag, New York, NY, USA. 
28. Ihaka R, Gentleman R. 1996. A language for data analysis and graphics. J Comput Graphical Stat 5:299-314.

29. Klepper O, Traas TP, Schouten AJ, Korthals GW, de Zwart D. 1999. Estimating the effect on soil organisms of exceeding noobserved effect concentrations (NOECs) of persistent toxicants. Ecotoxicology 8:9-21.

30. Krogh PH. 1995. Does a heterogeneous distribution of food or pesticide affect the outcome of toxicity tests with Collembola? Ecotoxicol Environ Saf 30:158-163.

31. Axelsen JA, Holst N, Hamers T, Krogh PH. 1997. Simulations of the predator-prey interactions in a two species ecotoxicological test system. Ecol Model 101:15-25.

32. Hamers T, Krogh PH. 1997. Predator-prey relationships in a twospecies toxicity test system. Ecotoxicol Environ Saf 37:203-212.

33. Lethbridge G, Pettit NM, Smith ARJ, Burns RG. 1976. The effect of organic solvents on soil urease activity. Soil Biol Biochem 8: 449-450.

34. Pritchard PH, Mueller JG, Lantz SE, Santavy DL. 1995. The potential importance of biodiversity in environmental biotechnologies applications: Bioremediation of PAH-contaminated soils and sediments. In Allsopp D, Colwell RR, Hawksworth DL, eds, Microbial Diversity and Ecosystem Function. CAB International, Wallingford, UK, pp 161-182.
35. Ma WC, Immerzeel J, Bodt J. 1995. Earthworms and food interactions on bioaccumulation and disappearance in soil of polycyclic aromatic hydrocarbons: Studies on phenanthrene and fluoranthene. Ecotoxicol Environ Saf 32:226-232.

36. Heemsbergen DA, Berg MP, Loreau M, van Hal JR, Faber JH, Verhoef HA. 2004. Biodiversity effects on soil processes explained by interspecific functional dissimilarity. Science 306: $1019-1020$

37. Kuzyakov Y, Friedel JK, Stahr K. 2000. Review of mechanisms and quantification of priming effects. Soil Biol Biochem 32:14851498.

38. Wiles JA, Krogh PH. 1998. Test with the collembolans Isotoma viridis, Folsomia candida and Folsomia fimetaria. In Løkke $\mathrm{H}$ Van Gestel CAM, eds, Handbook of Soil Invertebrate Toxicity Tests. John Wiley, Chichester, UK, pp 131-156.

39. Krogh PH, Axelsen JA. 1998. Test on the predatory mite Hypoaspis aculeifer preying on the collembolan Folsomia fimetaria. In Løkke H, Van Gestel CAM, eds, Handbook of Soil Invertebrate Toxicity Tests. John Wiley, Chichester, UK, pp 239-251.

40. International Organization for Standardization. 2004. Soil quality-Effects of pollutants on Enchytraeidae (Enchytraeus sp.) Determination of effects on reproduction and survival. ISO 16387. Geneva, Switzerland. 